\title{
THE CONSTITUTION OF THE RUSSIAN FEDERATION IN THE ASPECT OF REQUIREMENTS FOR RUSSIAN AS A STATE LANGUAGE
}

\author{
Sergey A. Kuznetsov \\ Saint Petersburg State University, Saint Petersburg, Russia \\ Aleksandr A. Solovyev \\ Saint Petersburg State University, Saint Petersburg, Russia
}

\begin{abstract}
On the results of the linguistic analysis of the text of the Constitution of the Russian Federation and the requirements that are imposed by legal discourse to the language of legal documents the authors reveal a set of obligatory characteristics of the language of the legal document, including definiteness, accuracy, clearness, stylistic neutrality, and language correctness. Application of these characteristics to assessing the quality of the text of Russian Constitution lead to finding some contextual gaps which might cause difficulties in understanding of some provisions in the basic law of the country. Violations of the accuracy and clarity of statements include those provisions of the Constitution in which lexical units are implemented in different meanings. In such cases, the distortion of meaning is possible at the stage of understanding (interpretation) of the verbal form. The articles of the Constitution also reveal a violation of clarity, which is accompanied by legal and linguistic uncertainty. The article provides examples of formulations that do not comply with the rules and norms of the use of language means in legal acts, as well as proposed ways to overcome these inconsistencies. It is argued that the development and application of a special linguistic methodology focused on communicative and rhetorical analysis of legally significant texts will allow more effective linguistic interpretation of normative legal acts, including the Constitution of the Russian Federation, as well as ensure uniformity of their application.

Key words: Constitution of the Russian Federation, linguistic interpretation of the text of the Constitution of the Russian Federation, regulatory legal act, criteria for assessing the language of normative legal acts, communicative-and-rhetorical analysis, Russian as a state language.
\end{abstract}

Citation. Kuznetsov S.A., Solovyev A.A. The Constitution of the Russian Federation in the Aspect of Requirements for Russian as a State Language. Vestnik Volgogradskogo gosudarstvennogo universiteta. Seriya 2. Yazykoznanie [Science Journal of Volgograd State University. Linguistics], 2019, vol. 18, no. 2, pp. 27-36. (in Russian). DOI: https://doi.org/10.15688/jvolsu2.2019.2.3

УДК 811.161.1:342.4

Дата поступления статьи: 18.01.2019

ББК $81.411 .2-55$

Дата принятия статьи: 12.03.2019

\section{КОНСТИТУЦИЯ РОССИЙСКОЙ ФЕДЕРАЦИИ В АСПЕКТЕ ТРЕБОВАНИЙ К РУССКОМУ ЯЗЫКУ КАК ГОСУДАРСТВЕННОМУ}

\author{
Сергей Александрович Кузнецов \\ Санкт-Петербургский государственный университет, г. Санкт-Петербург, Россия \\ Александр Александрович Соловьев \\ Санкт-Петербургский государственный университет, г. Санкт-Петербург, Россия
}

Аннотация. На примерах, полученных в результате лингвистического анализа текста Конституции Российской Федерации, с учетом требований, которые предъявляются юридической техникой к языку правового документа, в статье раскрыты такие обязательные признаки языка юридического документа, как определенность (точность), понятность (ясность) стилистическая нейтральность, языковая правильность. С примене- 
нием названных критериев оценки качества к тексту Конституции Российской Федерации обнаружены смысловые недочеты, приводящие к сложностям понимания отдельных положений Основного закона страны. Нарушения определенности и понятности высказывания выявлены в тех положениях Конституции, в которых лексические единицы реализуются в разных значениях. В таких случаях искажение смысла возможно на этапе интерпретации словесной формы. Показано, что в статьях Конституции нарушение понятности может сопровождаться юридико-лингвистической неопределенностью. В статье приведены примеры формулировок, не соответствующих правилам и нормам употребления языковых средств в правовых актах, а также предложены способы преодоления отмеченных несоответствий. Установлено, что разработка и применение специальной лингвистической методики, ориентированной на коммуникативно-риторический анализ юридически значимых текстов, позволит более эффективно осуществлять лингвистическое толкование нормативных правовых актов, включая Конституцию Российской Федерации, а также обеспечит единообразие их применения.

Ключевые слова: Конституция Российской Федерации, лингвистическое толкование текста Конституции РФ, нормативный правовой акт, критерии оценки языка нормативных правовых актов, коммуникативнориторический анализ, русский язык как государственный.

Цитирование. Кузнецов С. А., Соловьев А. А. Конституция Российской Федерации в аспекте требований к русскому языку как государственному // Вестник Волгоградского государственного университета. Серия 2, Языкознание. - 2019. - Т. 18, № 2. - C. 27-36. - DOI: https://doi.org/10.15688/jvolsu2.2019.2.3

\section{Лингвистический подход к анализу текста Конституции}

Конституция Российской Федерации занимает особое место в правовой системе нашей страны. В большинстве государств Основной закон выполняет не только формально нормативные функции, но и является программно-стратегическим документом - ядром формирования и развития политической, экономической и социальной системы. Этим объясняется то, что требования к языку конституции могут отличаться от обычных требований к языку нормативных правовых актов, выработанных юридической техникой.

Вместе с тем содержание ч. 1 ст. 15 Конституции Российской Федерации, согласно которой «Конституичия Российской Федерации имеет высшую юридическую силу, прямое действие и применяется на всей территории Российской Федерациии», требует, чтобы в России этот документ во всех его структурных элементах рассматривался и толковался именно как нормативный правовой акт, а не как «программа» или «декларация».

Такая двойственность целей и задач Конституции обязывает лингвиста подходить к анализу ее содержания с учетом ограничений, накладываемых на русский язык при его использовании в качестве государственного языка Российской Федерации, к которому предъявляются законодательно определенные требования.
Ядром русского литературного языка в функции государственного, выступает официально-деловой стиль. Он реализуется в дипломатических, юридических документах, инструкциях, распоряжениях и иных официальных бумагах, обеспечивая максимальную понятность и нейтральность актов коммуникации. Формирующие его вербальные средства позволяют с исчерпывающей полнотой выражать в документах любые социально значимые смыслы, но и, что не менее важно, делают их незаменимым инструментом во взаимодействии государства и общества, обеспечивая функции государственного языка в тех сферах его использования, которые перечислены в ст. 3 Федерального закона «О государственном языке Российской Федерации» [Федеральный закон от 01.06.2005 № 53-Ф3, ст. 3, ч. 1, п. 1-10].

К текстам, написанным на русском языке в функции государственного, предъявляются такие требования, которые призваны исключить двусмысленность и возможные разночтения. Построенные по образцам и правилам официально-делового стиля, они должны представлять собой результат последовательного отбора слов и словосочетаний, объединенных в высказывания, лишенные индивидуальности, но имеющие предсказуемый однотипно извлекаемый смысл. Следовательно, отличительные черты лучших текстов рассматриваемой сферы - точность, конкретность, четкость формулировок и лаконичность изложения. 
Применительно к официальным документам неоднократно подчеркивалось, что полное и всестороннее использование лингвистических методов и приемов их подготовки является объективной необходимостью. Однако опыт их применения накоплен по отношению к юридически значимым документам. Именно этот опыт (он на сегодняшний день наиболее полный) предлагается учитывать при оценке практической значимости имеющихся рекомендаций, к их распространению на ту часть русского языка, которая репрезентирует государственный язык Российской Федерации.

\section{Критерии оценки качества языка нормативных правовых актов}

Существующие нормы современного русского литературного языка, являющиеся для юридической техники обязательными (см. положения ч. 6 ст. 1 и п. 5 ч. 1 ст. 3 в [Федеральный закон от 01.06.2005 № 53-Ф3], получают в юриспруденции уточнения. Так, в законодательных актах специальной регламентации подвергаются правила структурирования, порядок конструирования и употребления терминологии, использования грамматических форм и построения риторических конструкций, порядок применения стилистически маркированных средств, присущих официально-деловому стилю и др. Вызвано это тем, что язык законов, в отличие, например, от языка науки, должен быть понятен неопределенно широкому кругу лиц, поскольку правовые акты предназначены не столько для специалистов, сколько для тех, кто не знает тонкостей юридической терминологии и риторики. Для языка Конституции это положение особенно верно, поэтому требования точности, ясности, конкретности, четкости и логичности формулировок, предъявляемые юридической техникой, преобразованы нами в лингвистически значимые критерии соответствия формы высказывания выражаемому ею смыслу.

Можно утверждать, что язык законов, реализованный в единицах речевой цепи (словах, словосочетаниях, предложениях, высказываниях), должен соответствовать следующим критериям: определенность (точность), понятность (ясность), стилистическая нейтральность, языковая правильность.

Определенность (точность) текста проявляется в использовании таких словесных характеристик объекта описания, которые указывают на необходимые и достаточные признаки, отличающие данный объект, семантические признаки, объединяющие его с другими объектами того же класса, позволяя сопоставить содержание понятия и выделяемые им признаки объекта с аналогичными объектами.

В соответствии с этим критерием следует соблюдать правило употребления термина в одном значении (правило однозначности), а также понятийно-логические правила составления дефиниций (соразмерность содержания определяемого понятия и определения, отказ от тавтологии и др.). При формулировании правовых предписаний необходимо, избегая лексической избыточности и понятийносмысловых повторов, добиваться точного соблюдения содержательной связанности текста в рамках абзаца.

Понятность (ясность) проявляется в отборе словесных средств, которые характеризуют объем понятия, обеспечивают мысленную воспроизводимость объекта описания, исключающую многозначность (двусмысленность) понимания и неопределенность применения положений закона. Данный критерий включает также требования использования общеизвестных слов в основных, «словарных» значениях, отказа от употребления без объяснения значений иностранных слов и узкоспециальных терминов, не освоенных русским литературным языком, от малоинформативных словосочетаний и употребления нелогичных, «каламбурных» словосочетаний. Требуется соблюдать правило толкования неизвестного понятия через известное родовое. При анализе текста следует адекватно интерпретировать синтаксические конструкции с прямым порядком слов и стандартными коммуникативно-риторическими структурами, включающими модальности дозволения, обязывания и запрета.

Стилистическая нейтральность правового акта означает, что объект описания получил словесную характеристику с использованием таких речевых единиц, семантико- 
стилистические качества которых соответствуют официально-деловой сфере общения. Текст, составленный по правилам юридически значимого документа, отличается директивностью и безличностью изложения, не содержит словоупотреблений с эмоциональноэкспрессивной (оценочной) окраской, присущей языку художественного произведения, или функционально-стилевых коннотаций, свойственных разговорному, просторечному или диалектному стилю речи.

Языковая правильность характеризует форму высказывания, позволяющую так изложить требуемое содержание, чтобы разногласия в понимании смысла той или иной словесной конструкции могли быть сняты путем развернутого толкования (интерпретации), логично соотносящего языковую форму с ее значением. В этом критерии заложены требования нормативного словоупотребления и точного соблюдения логико-грамматической связанности текста в рамках предложения, которая регулируется действующими правилами орфографии и пунктуации русского языка.

Применяя вышеперечисленные критерии оценки качества к тексту Конституции Российской Федерации, можно обнаружить смысловые недочеты, приводящие к определенным трудностям в понимании отдельных положений Основного закона страны.

\section{Нарушения определенности и понятности высказывания}

Нарушения определенности и понятности высказывания отмечены в тех положениях Конституции, в которых лексические единицы реализуются в разных значениях, то есть один словесный знак наполнен неодинаковым содержанием. В таких случаях искажение смысла языкового выражения происходит на этапе понимания (интерпретации) словесной формы. Наиболее ясным примером здесь может служить слово народ, которое в статьях Основного закона встречается 11 раз.

Так, в преамбуле и в ст. 3 Конституции это слово, будучи использовано в определительной конструкции многонациональный народ, выражает значение 'население какой-л. страны':
(1) Мы, многонациональный народ Российской Федерации (Преамбула);

(2) Носителем суверенитета и единственным источником власти в Российской Федерации является ее многонациональный народ (ст. 3, ч. 1).

Слово народ в форме множественного числа (употреблено 5 раз) реализует значение 'народность, национальная группа':

(3) исходя из общепризнанных принципов равноправия и самоопределения народов (Преамбула);

(4) Федеративное устройство Российской Федерации основано на ее государственной целостности, единстве системы государственной власти, разграничении предметов ведения и полномочий между органами государственной власти Российской Федерации и органами государственной власти субъектов Российской Федерации, равноправии и самоопределении народов в Российской Федерации (ст. 5, ч. 3);

(5) Земля и другие природные ресурсы используются и охраняются в Российской Федерации как основа жизни и деятельности народов, проживающих на соответствующей территории (ст. 9);

(6) Российская Федерация гарантирует всем ее народам право на сохранение родного языка, создание условий для его изучения и развития (ст. 68, ч. 3);

(7) Российская Федерация гарантирует права коренных малочисленных народов в соответствии с общепризнанными принципами и нормами международного права и международными договорами Российской Федерации (ст. 69).

Слово народ используется в форме единственного числа без определения (5 раз):

(8) Народ осуществляет свою власть непосредственно, а также через органы государственной власти и органы местного самоуправления (ст. 3, ч. 2);

(9) Высшим непосредственным выражением власти народа являются референдум и свободные выборы (ст. 3, ч. 3);

(10) При вступлении в должность Президент Российской Федерации приносит народу следующую присягу: «Клянусь при осуществлении полномочий Президента Российской Федерации уважать и охранять права и свободы человека и гражданина, соблюдать и защищать Конституцию Российской Федерации, защищать суверенитет и независимость, безопасность и целостность государства, верно служить народу» (ст. 82, ч. 1). 
С.А. Кузнецов, А.А. Соловьев. Конституция РФ в аспекте требований к русскому языку как государственному

В приведенных фрагментах Конституции возникает контекстная неопределенность объема понятия «народ», позволяющая произвольно трактовать содержание всей конституционной нормы. Ср.:

- в (8): *Народ [= население / нация, народность / основная трудовая масса населения, жители той или иной местности, территории / люди] осуществляет свою власть непосредственно, а также через органы государственной власти и органы местного самоуправления»;

- в (9): Высшим непосредственным выражением власти *народа [= населения / нации, народности / основной трудовой массы населения, жителей той или иной местности, территории / людей] являются референдум и свободные выборы;

- в (10): При вступлении в должность Президент Российской Федерации приноcum * народу [= населению / нации, народности / основной трудовой массе населения, жителям той или иной местности, территории / людям] следующую присягу: «Клянусь при осуществлении полномочий Президента Российской Федерации уважать и охранять права и свободы человека и гражданина, соблюдать и защищать Конституиию Российской Федерации, защищать суверенитет и независимость, безопасность и иелостность государства, верно служсить * народу [= населению / нации, народности / гражданам / основной трудовой массе населения, жителям той или иной местности, территории / людям]».

Для того чтобы избежать существующей неопределенности объема понятия, во всех этих случаях следовало бы использовать слово граждане в форме множественного числа, которое в рассматриваемых контекстах имело бы вполне определенное значение. Например: Граждане Российской Федерации осуществляют свою власть непосредственно, а также через органы государственной власти и органы местного самоуправления.

Определенность и понятность нарушены и при употреблении слова момент. В Конституции Российской Федерации оно встречается 9 раз. В 7 случаях это слово обозначает временную точку начала того действия, которое она ограничивает, например:
(11) с момента принесения им присяги (ст. 92, ч. 1);

(12) с момента досрочного прекращения исполнения полномочий (ст. 92, ч. 2);

(13) с момента начала работы Государственной Думы (ст. 99, ч. 4).

Два раза слово момент, характеризуя не начало действия, а событие целиком, используется понятийно и стилистически некорректно:

(14) с момента соответственно задержания, заключения под стражу или предъявления обвинения (ст. 48, ч. 2);

(15) Никто не может нести ответственность за деяние, которое в момент его совершения не признавалось правонарушением (ст. 54, ч. 2).

Причина смысловой неопределенности нормы, зафиксированной в конституции, заключена в обстоятельстве времени, выраженном предложно-падежной формой в момент, которая не может обозначать 'временной период, необходимый для совершения определенного действия'. Более точной была бы форма во время. Ее использование помогло бы снять разговорный оттенок фразы и неопределенность: Никто не может нести ответственность за деяние, которое во время его совершения не признавалось правонарушением.

К нарушению понятности конституционной нормы следует отнести многозначность, возникающую при ошибках употребления модальных слов, например:

(16) Никто не должен подвергаться пыткам, насилию, другому жестокому или унижающему человеческое достоинство обращению или наказанию. Никто не может быть без добровольного согласия подвергнут медицинским, научным или иным опытам (ст. 21, ч. 2).

В этой статье законодатель по-разному оформил две одинаковые в смысловом отношении ситуации. Рассмотрим результат имеющихся различий. Во-первых, модальное значение предложения Никто не должен подвергаться пыткам, насилию, другому жестокому или унижающему человеческое достоинство обращению или наказанию может быть интерпретировано в соответствии с одним из словарных значений слова должен как 
необязательность осуществления действия (*никто не обязан подвергаться пыткам) и рекомендация запрета на осуществление действия (*никого не следует подвергать пыткам). Во-вторых, поскольку такая конструкция (одушевленный объект с отрицанием долженствования при пассивной инфинитивной форме глагола) используется в Конституции только один раз, это вносит дополнительную неопределенность в толковании предложения, тем более что в следующем предложении законодатель правильно применяет модальность полного запрета на осуществление действия (Никто не может быть ... подвергнут...), употребляя для этого конструкцию, образующуюся при помощи личной формы модального глагола мочь, инфинитива вспомогательного глагола быть и краткой формы страдательного причастия прошедшего времени в качестве смысловой части составного сказуемого. Приведем несколько примеров реализации этой конструкции (в Конституции она используется 17 раз):

(17) До судебного решения лицо не может быть подвергнуто задержанию на срок более 48 часов (ст. 22, ч. 2);

(18) Никто не может быть принужден к определению и указанию своей национальной принадлежности (ст. 26, ч. 1);

(19) Никто не может быть лишен своего имущества иначе как по решению суда (ст. 35, ч. 3).

\section{Юридико-лингвистическая неопределенность правовой нормы}

В статьях Конституции обнаруживается нарушение понятности, которое сопровождается юридико-лингвистической неопределенностью:

(20) В Российской Федерации признается и гарантируется местное самоуправление. Местное самоуправление в пределах своих полномочий самостоятельно. Органы местного самоуправления не входят в систему органов государственной власти (ст. 12).

Во-первых, словосочетание местное самоуправление используется здесь в трех метонимичных значениях. В первом предложении оно номинирует 'деятельность граждан, обеспечивающая им самостоятельное, без вмешательства извне устройство и улаживание дел какой-л. хозяйственной, административной единицы, организации и т. п.' (сопоставляется с понятием «субъектная деятельность»). Во втором предложении это словосочетание выражает значение 'люди, наделенные полномочиями самостоятельного решения вопросов внутреннего законодательства и управления' (соотносится с понятием «субъект деятельности»). В третьем предложении реализуется значение 'система выборных учреждений, наделенных полномочиями самостоятельно решать финансовые, хозяйственные, административные дела какой-л. организации, какой-л. территории и т. п.' (соотносится с понятием «структурно-организационный объект»).

Во-вторых, юридико-лингвистическая неопределенность этой статьи Конституции возникает из-за того, что в пассивной конструкции первого предложения термин «Российская Федерация» используется в территориально-пространственном значении, поэтому позиция агенса действия остается незамещенной. В результате остается непонятным, кем признается и гарантируется деятельность местного самоуправления.

Совмещение понятийной и юридико-лингвистической неопределенности возникает в тех статьях Конституции, где позиция агенса остается незаполненной:

(21) В Российской Федерации признается идеологическое многообразие (ст. 13, ч. 1);

(22) В Российской Федерации признаются политическое многообразие, многопартийность (ст. 13, ч. 3).

Всего в Основном законе насчитывается 11 статей, в которых используется пассивная конструкция с такой неопределенностью (ст. 7 , ч. 2 ; ст. 8 , ч. 1 и 2 ; ст. 9 , ч. 1 ; ст. 13 , ч. 1 и 3 ; ст. 17 , ч. 1 ; ст. 41 , ч. 2 ; ст. 45 , ч. 1 ; ст. 55 , ч. 2 ; ст. 63 , ч. 2 ).

Поскольку законодателем Конституции выступает многонациональный народ, то есть все граждане России, постольку юридико-лингвистическая неопределенность агенса приобретает особую двусмысленность, тем более что в необходимых случаях законодатель использует вполне конкретные конструкции, ср.: 
(23) Российская Федерация обеспечивает целостность и неприкосновенность своей территории (ст. 4, ч. 3).

В тексте Конституции имеются фрагменты, в которых языковая правильность нарушается по нескольким критериям. Ярким примером этого является преамбула:

(24) Мы, многонациональный народ Российской Федерации, соединенные общей судьбой на своей земле, утверждая права и свободы человека, гражданский мир и согласие, сохраняя исторически сложившееся государственное единство, исходя из общепризнанных принципов равноправия и самоопределения народов, чтя память предков, передавших нам любовь и уважение к Отечеству, веру в добро и справедливость, возрождая суверенную государственность России и утверждая незыблемость ее демократической основы, стремясь обеспечить благополучие и процветание России, исходя из ответственности за свою Родину перед нынешним и будущими поколениями, сознавая себя частью мирового сообщества, принимаем КОНСТИТУЦИЮ РОССИЙСКОЙ ФЕДЕРАЦИИ (Преамбула).

Так, фраза Мы, многонацииональный народ Российской Федерайии, соединенные общзей судьбой на своей земле построена с нарушением согласования причастного оборота при обособленном приложении. Здесь требуется согласовать причастную форму соединенные со словом народ, а не с местоимением $\boldsymbol{M b l}$, так как уточнению подлежит именно обособленное приложение. В соответствии с правилами согласования слов этот фрагмент должен иметь иное, чем в тексте преамбулы, грамматическое оформление: Mbl, многонациональный народ Российской Федерации, соединенный общей судьбой на своей земле.

Кроме того, дважды употребленная деепричастная форма действительного залога несовершенного вида настоящего времени от непереходного глагола утверждать используется в разных значениях. Первый раз (утвержждая права и свободы человека, гражданский мир и соглаcue) деепричастие означает 'официально принимая окончательное решение, признавая окончательно установленным', второй (утверждая незыблемость ее демократической основы) - 'устанавливая, вводя на прочных основаниях, окончательно упрочивая'.

В деепричастном обороте исходя из, используемом в функции предлога: исходя из ответственности за свою Родину перед нынешним и будущими поколениями, значение 'беря что-л. за основу; основываясь на чем-л.' не реализуется (в преамбуле оно представлено в конструкции: исходя из общепризнанных принципов равноправия $и$ самоопределения народов...). В данном случае только деепричастные формы глаголов понимать, сознавать могут выразить необходимое языковое значение, соотносимое со значением слова ответственность. Ср: сознавая / понимая ответственность за свою Родину перед нынешним и будушчими поколениями.

Деепричастный оборот сознавая себя частью мирового сообщества является понятийно неоднородным с предыдущими восьмью оборотами и семантически не связанным с прямым дополнением характеризуемого глагола принимать. Ср.: *сознавая себя частью мирового сообщества, принимаем (?Конституичюю Российской Федераичuи).

Нарушения требований точности высказывания обнаруживаются в результате анализа особенностей употребления синонимичных имен Российская Федерация (581 раз) - Россия (6 раз) и слова государство (27 раз). В тексте Конституции, несмотря на заявленную законодателем равнозначность имен (ср. ст. 1, ч. 2 Конституции Российской Федерации: Наименования Российская Федерация и Россия равнозначны), наименование Российская Федерация используется в качестве единственного официального имени. Наименование Россия самостоятельно употребляется только в преамбуле (2 раза), в остальных случаях оно используется исключительно в качестве уточнения:

(25) Одновременно прекращается действие Конституции (Основного закона) Российской Федерации - России, принятой 12 апреля 1978 года, с последующими изменениями и дополнениями (разд. 2, п. 1).

Кроме закономерных случаев, когда наименование Российская Федерация в дефини- 
циях толкуется через родовое понятие государство:

(26) Российская Федерация - светское государство (ст. 14, ч. 1),

или в определенном контексте Российская Федераџия и государство получают один и тот же понятийный объем:

(27) Президент Российской Федерации является главой государства (ст. 80, ч. 1),

конституционная норма, оформленная как общий принцип, содержит элемент декларативной неопределенности:

(28) Признание, соблюдение и защита прав и свобод человека и гражданина - обязанность государства (ст. 2);

(29) Достоинство личности охраняется государством (ст. 21, ч. 1).

Представляется, что формулировки типа Российская Федерация обеспечивает защчту прав и свобод человека и гражданина; Достоинство личности охраняется законами Российской Федерации логически более обоснованны, поскольку в качестве диспозиционной нормы заявлено, что Человек, его права и свободы являются высшей иенностью (ст. 2), а в ст. 19 содержится норма, согласно которой Государство гарантирует равенство прав и свобод человека и гражданина независимо от пола, расы, национальности, языка, происхождения, имущуественного и должностного положения, места жительства, отношения к религии, убеждений, принадлежности к общественным объединениям, а также других обстоятельств. Запрещаются любые формы ограничения прав граждан по признакам соииальной, расовой, национальной, языковой или религиозной принадлежнос$m и$ (ст. 19, ч. 2).

Контексты, в которых использован термин государство, не всегда однозначно позволяют ответить на вопрос: с каким именно референтом соотносится та или иная ситуация? Неопределенность референта становится особенно явной, если учитывать, что «государствами» в ч. 2 ст. 5 Конституции
Российской Федерации (республика (государство) имеет свою конституциюю и законодательство) называются отдельные республики в составе России. Эта неопределенность означает неопределенность того, кто согласно упомянутой норме обязан обеспечивать выполнение тех или иных конкретных обязательств и за счет каких средств - Российская Федерация (за счет федерального бюджета) или же республики в составе России (за счет своих региональных бюджетов)?

Принцип экономии языковых средств, исключающий лексическую избыточность, повторы и малоинформативные словосочетания, нарушается в нескольких статьях Конституции. Например:

(30) Президент Российской Федерации является гарантом Конституции Российской Федерации, прав и свобод человека и гражданина. В установленном Конституцией Российской Федерации порядке он принимает меры по охране суверенитета Российской Федерации, ее независимости и государственной целостности, обеспечивает согласованное функционирование и взаимодействие органов государственной власти (ст. 80, ч. 2);

(31) Клянусь при осуществлении полномочий Президента Российской Федерации уважать и охранять права и свободы человека и гражданина, соблюдать и защищать Конституцию Российской Федерации, защищать суверенитет и независимость, безопасность и целостность государства, верно служить народу (ст. 82, ч. 1).

В (30) слово суверенитет ('полная независимость государства от других государств в осуществлении своей внутренней и внешней политики') употребляется в значении синонимичном значению слова независимость ('политическая самостоятельность, отсутствие подчиненности; суверенитет').

В юридической технике принято считать, что использование для обозначения одного понятия разных лексических единиц увеличивает неопределенность правовой нормы. Следует отметить, что в Конституции слово $c y$ веренитет от статьи к статье употребляется в разных значениях. Независимость является лишь одним из обязательных свойств, качеств суверенной власти, которая включает, например, еще и признак верховенства. Акцент на этом свойстве суверенитета, 'праве 
верховной власти управлять чем-л., повелевать кем-л., подчинять своей воле' обнаруживается в других нормах:

(32) Носителем суверенитета и единственным источником власти в Российской Федерации является ее многонациональный народ (ст. 3, ч. 1);

(33) Суверенитет Российской Федерации распространяется на всю ее территорию (ст. 4, ч. 1).

Принципы экономии языковых средств и исключения многозначности нарушаются в ст. 7, которую разберем более подробно.

(34) Российская Федерация - социальное государство, политика которого направлена на создание условий, обеспечивающих достойную жизнь и свободное развитие человека (ст. 7, ч. 1).

Здесь обращает на себя внимание выражение создание условий, обеспечиваюшзих достойную жизнь, в котором значение словосочетания создание условий совпадает со значением причастной формы глагола обеспечивать в словосочетании обеспечиваюших достойную жизнь. Ср.: создать условия означает 'сделать возможным появление, возникновение чего-л.; обеспечить наличие чего-либо'; обеспечить достойную жизнь - 'создать все необходимые условия для осуществления чего-л.; гарантировать надежность, прочность чего-либо'. Согласно правилам юридической техники этот фрагмент статьи Конституции следовало бы изложить в редакции создание условий для достойной жизни либо обеспечения достойной жизни.

Что касается формулировки создание условий, обеспечивающих достойную жизнь, то такая усложненная конструкция нивелирует гарантии достойной жизни (поскольку государство не «обеспечивает», а лишь «создает условия для обеспечения»). Это позволяет сделать вывод о том, что вопрос собственно «обеспечения» достойной жизни - это уже не компетенция государства в лице его органов («обеспечением» может заниматься кто угодно, необязательно государство). Таким образом, коммуникативно-риторический анализ свидетельствует о стремлении авторов текста Конституции уменьшить ее социальную направленность.
Следует заметить также, что расматриваемый фрагмент содержит принципиально неопределенное понятие «достойная жизнь». Можно предположить, что в связке достойная жизнь и свободное развитие человека законодатель дал характеристику как экономическим (достойная жизнь), так и духовным (свободное развитие человека) аспектам жизни. При таком понимании смысла статьи достойной является жизнь, при которой обеспечены материальные потребности человека. Однако данная интерпретация словосочетания может быть оспорена ввиду его полной неопределенности.

\section{Выводы}

Обнаруженные в тексте Конституции Российской Федерации речевые ошибки, нарушающие требования ясности, точности, конкретности, правильности и логичности формулировок, хотя и не разрушают ни общего смысла текста, ни коммуникативной связи государства и общества, однако демонстрируют невысокое качество редакционнотехнической подготовки действующего Ocновного закона.

K сожалению, в России до сих пор отсутствует специальный законодательный акт, устанавливающий правила и методику подготовки и интерпретации нормативных правовых актов. В отсутствие такого документа, позволяющего отличать лингвистически обоснованные трактовки текста от произвольных объяснений значений речевых структур, невозможно заранее устанавливать наличие смысловых рассогласований между той нормой права, которую законодатель хочет воплотить, и ее фактической реализацией. Встречающиеся в нормативных актах ошибки, несоответствия и противоречия между идеей законодателя и ее изложением в тексте закона дискредитируют законодателя, поскольку в таких случаях нарушаются не только обозначенные выше конституционные принципы, но и основные положения Федерального закона от 01.06.2005 № 53-Ф3 «О государственном языке Российской Федерации». Все это может негативно отражаться на оценке деятельности органов государственной власти, 


\section{ГЛАВНАЯ ТЕМА НОМЕРА}

снижать в общественном мнении авторитет как отдельных представителей власти, так и государства в целом.

\section{СПИСОК ЛИТЕРАТУРЫ}

Федеральный закон от 01.06.2005 № 53-Ф3 «О государственном языке Российской Федерации» (ред. от 05.05.2014). URL: http://pravo.gov.ru / proxy $/$ ips $/$ ?docbody $=\&$ firstDoc $=1 \&$ lastDoc $=$ 1\&nd=102092715 (дата обращения: 13.05.2019).

\section{ИСТОЧнИк}

Конституция Российской Федерации. URL: http:// publication.pravo.gov.ru/Document/View/ 0001201408010002 (дата обращения: 13.05.2019).

\section{REFERENCES}

Federalnyy zakon ot 01.06.2005 № 53-FZ «O gosudarstvennom yazyke Rossiyskoy Federatsii» (red. ot 05.05.2014) [Federal Law of 1 June 2005 no. 53-FZ "On the State Language of the Russian Federation" (As Amended on 5 May 2014)]. URL: http://pravo.gov.ru /proxy/ips/ ?docbody $=$ \&firstDoc $=1$ \&lastDoc $=1$ \&nd $=102092715$ (accessed 13 May 2019).

\section{SOURCE}

Konstitutsiya Rossiyskoy Federatsii [The Constitution of the Russian Federation]. URL: http:// publication.pravo.gov.ru/Document/View/ 0001201408010002 (accessed 13 May 2019).

\section{Information about the Authors}

Sergey A. Kuznetsov, Doctor of Sciences (Philology), Director of the Communicative Competence Centre, Saint Petersburg State University, Universitetskaya Emb., 7-9, 199034 Saint-Petersburg, Russia, s.kuznetsov@spbu.ru, sakuzn@yandex.ru,https://orcid.org/0000-0002-4096-503X

Aleksandr A. Solovyev, First Deputy in Legal Affairs of the Vice-Rector, Head of the Apparatus of Rector, Saint Petersburg State University, Universitetskaya Emb., 7-9, 199034 Saint-Petersburg, Russia, salex@jurfak.spb.ru, https://orcid.org/0000-0002-6202-2163

\section{Информация об авторах}

Сергей Александрович Кузнецов, доктор филологических наук, директор Центра коммуникативных компетенций, Санкт-Петербургский государственный университет, Университетская наб., 7-9, 199034 г. Санкт-Петербург, Россия, s.kuznetsov@spbu.ru, sakuzn@yandex.ru, https://orcid.org/0000-0002-4096-503X

Александр Александрович Соловьев, первый заместитель по правовым вопросам проректора-руководителя Аппарата ректора, Санкт-Петербургский государственный университет, Университетская наб., 7-9, 199034 г. Санкт-Петербург, Россия, salex@jurfak.spb.ru, https://orcid.org/0000-0002-6202-2163 